Article

\title{
Physical Activity and Commuting to School in Spanish Nine-Year-Old Children: Differences by Gender and by Geographical Environment
}

\author{
Jesús Martínez-Martínez ${ }^{1}$, Susana Aznar ${ }^{2, *(\mathbb{D})}$, Sixto González-Víllora ${ }^{3}{ }^{\mathbb{D}}$ and \\ Guillermo F. López-Sánchez ${ }^{4, *(D)}$ \\ 1 Faculty of Education of Toledo, University of Castilla-La Mancha, 45071 Toledo, Spain; \\ Jesus.MMartinez@uclm.es \\ 2 Faculty of Sports Sciences, University of Castilla-La Mancha, 45071 Toledo, Spain \\ 3 Faculty of Education of Cuenca, University of Castilla-La Mancha, 16071 Cuenca, Spain; \\ Sixto.Gonzalez@uclm.es \\ 4 Faculty of Sport Sciences, University of Murcia, 30720 Murcia, Spain \\ * Correspondence: Susana.Aznar@uclm.es (S.A.); gfls@um.es (G.F.L.-S.)
}

Received: 20 October 2019; Accepted: 10 December 2019; Published: 11 December 2019

check for updates

\begin{abstract}
Children's health status is related to their physical activity levels. Active commuting is associated with higher physical activity and reduced risk of all-cause mortality, cardiovascular disease incidence, and diabetes. The objective of this research was to study the levels of physical activity and the commuting to school (active vs. passive) in Spanish nine-year-old children, analyzing the differences by gender and by the geographical environment where they live (rural or urban environment). Accelerometry was used for the measurement of physical activity: Sedentary time (min/day), vigorous physical activity (min/day), moderate to vigorous physical activity (min/day), intensity (counts/min), steps (number). The questionnaire of the European Youth Heart Study (EYHS) was used to determine the geographical environment (city/urban, residential area/outside city, rural/village) and the modes of transport (active: Walking and bicycle, passive: Car, motorcycle, public transport). A total of 455 Spanish nine-year-old children ( 247 girls and 208 boys) belonging to the EYHS participated in this study. The results showed that boys were significantly more physically active than girls $(p \leq 0.001)$. Results also showed that active commuting to school was positively correlated with the levels of physical activity $(r=0.324, p \leq 0.001)$. The geographical environment influenced the way in which children went to school, being active commuting to school significantly ( $p \leq 0.001$ ) less frequent in those children who lived in a rural environment $(22.4 \%)$ than in those who lived in the city $(57.1 \%)$ or in a residential area $(62.7 \%)$. As active commuting to school means increasing levels of physical activity in both sexes, strategies should be implemented in order to encourage active commuting to schools, contributing at the same time to better health and sustainability of future generations.
\end{abstract}

Keywords: physical activity; transport; children; environmental factors; accelerometer

\section{Introduction}

Active commuting to and from school (walking or by bicycle), in opposition to passive commuting (such as motorized transportation), has been proposed as a way to increase physical activity in children and adolescents [1-4], with the purpose of preventing cardiovascular diseases that are associated with higher mortality [5-7]. A recent review [8] on interventions to promote active school transport, highlighted the use of active commuting to school as an opportunity to increase children's physical 
activity levels. Despite the well-known benefits of physical activity, recent research has showed a decrease in the active commuting rates to and from school [9-11].

An important issue which predicts active commuting to school is the distance from home to school. Recent research in Spain has stated that the threshold distance for walking to school was $875 \mathrm{~m}$, 0.54 miles, in children, and it was higher among urban $(1250 \mathrm{~m}, 0.78$ miles $)$ than rural participants ( $675 \mathrm{~m}, 0.42 \mathrm{miles)}$ [12]. Moreover, there is some controversy as to how distance to school can play an important role to counteract sedentary behavior. Hinckson et al. [13] indicated that distance to school was an important factor related to physical activity levels, where 1 to $2 \mathrm{~km}$ from school together with active commuting could be useful to counteract children's sedentary behaviors. However, for physically active children, active commuting does not seem to be as relevant.

Low traffic density and route safety are positively associated with active school travel, but also positive parental views on active commuting, as well as high level of social interactions within the neighborhood, may play an important role to promote active school travel [11]. Moreover, the automobile culture as a mode of habitual transport has driven risk factors such as air pollution, considered the most important of the environmental risk factors to which humans are exposed [14]. A high level of air pollution can make it unpractical or near impossible for children to walk or cycle to school, sports practice, or their friends' houses $[10,15,16]$. There are also other factors that influence the way of transport, such as environmental characteristics, traffic, distance, and security/safety of the road [17].

However, despite all the previously mentioned barriers, the aspects that support children's active commuting to school are encouraged by providing child-friendly social and built environments, safety from traffic, and policies that promote local schools and safe vehicle-free zones around school [18].

Active commuting can then become an opportunity to increase children's physical activity levels helping them to reach the WHO recommendations on physical activity for health [5]. These recommendations indicate that the age group from 5 to 17 years old should accumulate $60 \mathrm{~min}$ of moderate to vigorous physical activity (MVPA) daily. It is encouraging how some governmental organizations and cities have focused part of their interests and concerns on this matter, providing and implementing active transport strategies, with the clear intention of protecting citizens' health and sustainable development $[9,10]$. However, an objective assessment is still necessary.

The objective of this research was to study the levels of physical activity and the commuting to school (active vs. passive) in Spanish nine-year-old children, analyzing the differences by gender and the geographical environment where they live (rural or urban environment).

\section{Methods}

\subsection{Participants and Recruitment Process}

The sample of this research is part of the EYHS research (European Youth Heart Study). The EYHS is a school-based, cross-sectional study designed to examine the interactions between personal, environmental, and lifestyle influences on the risk factors for future cardiovascular diseases in several European countries.

All eligible schools were stratified according to location (urban, suburban, and rural: Rural: $<10,000$ people, suburban: 10,000-100,000 people, urban: $>100,000$ people) and the socioeconomic profile of the uptake area (high, middle, and low). The study sample was randomly selected using a two-stage cluster sample procedure, with schools in Madrid as primary sampling units. The secondary units were the children within the schools, and equal numbers of children were sampled randomly from each school.

For each EYHS site, the goal was to reach 1000 children from 20 schools. A possible mortality rate of $20 \%$ was taken into consideration and, therefore, the sample size was increased accordingly. In the community of Madrid, there were 1127 schools at the time of data collection distributed in five areas: Madrid Capital, Madrid North, Madrid South, Madrid East, and Madrid West. 
The distribution of the 1127 schools by population density was the following: 103 schools in rural areas ( $<10,000$ citizens), 273 schools in semi-urban areas (10,000-100,000 citizens), and 751 schools in urban areas ( $>100,000$ citizens). At the year of data collection, there were 53,620 students from the community of Madrid, and therefore, we needed to select 600 students $+20 \%$ for possible mortality rates, a total sample of 720 students. Assuming that each class had 25 students, 29 primary schools were needed for the study. When adjusted by population density, the sample included three schools in rural areas, seven in semi-urban areas, and 19 in urban areas.

Finally, a total of 455 nine-year-old children participated in the study: 247 girls (9.25 \pm 0.59 years) and 208 boys $(9.02 \pm 0.22$ years). All children provided accelerometry data $(n=455)$, but EYHS questionnaire was completed by only 387 of the 455 participants (15\% of missing values in the questionnaire) because the other 68 children did not attend the questionnaire evaluation session. Prior to data collection, children's verbal consent was obtained to participate in this study. Ethical approval was obtained by the Health Institute Carlos III (Madrid, Spain) and parental informed consent was obtained for each participant prior to data collection.

\subsection{Measures}

\subsubsection{Physical Activity}

Physical activity was measured during seven consecutive days using accelerometers GT1M. All children wore the accelerometer during the daytime, except while bathing or during other aquatic activities. Verbal and written instructions for care and placement of the monitor were given to both, children and their parents. For data to be considered valid, two criteria were established: A minimum of data for a period of four days including one weekend day and a minimum of 10 registered hours of data per day [19]. Count ranges for the various activity intensities were: 0-499 for sedentary, 500-1999 for light, 2000-2999 for moderate, 3000-4499 for vigorous, and 4500-32,767 for very vigorous activities, according to Andersen et al. [20]. To analyze the accelerometer data, Kinesoft software, developed specifically for the Actical and Actigraph accelerometers, was used. The outcome variables were sedentary time ( $\mathrm{min} /$ day), vigorous physical activity ( $\mathrm{min} /$ day), moderate to vigorous physical activity (min/day), intensity (counts/min) and steps (number). We calculated mean counts per minute by dividing the sum of total counts per epoch ( $15 \mathrm{~s}$ ) for a valid day by the number of minutes of wear time on that day across all valid days. We excluded from the analysis bouts of 20 continuous minutes of activity with intensity counts of 0 , considering these periods to be non-wearing time.

To support the accelerometry data, the children had a diary at school to complete, with the teacher's help, information related to wear and non-wear time.

\subsubsection{Physical Activity During the Commuting to the School}

For this process, we extracted all the data collected during the day, and those that corresponded with the school entry schedule within the registration days of each subject and according to the school schedule of each educational center and subjects analyzed. Thus, it was established as a timetable for the arrivals one hour before school hours (08:00 to 09:00 AM), in order to cover all students regardless of the geographical environment or modes of transport. It was decided to measure physical activity during the commuting to the school only at the arrival time and not at the departure time because departure time of each subject depended on several factors, such as different departure time in different schools, different departure time in different days of the week, different departure time for those children attending school canteen, different departure time for those children attending after-school activities.

\subsubsection{Geographical Environment}

The validated EYHS questionnaire [21] was used. The questionnaire was individually answered by all students. The questionnaire was computer-based. Each child was assisted by a researcher to 
answer the questions and receive help if needed. If the student did not answer one question, he/she could not move to the next, unless the researcher helped him/her to continue. In this way, we could determine if the child understood the questions. The format of the questions included drawings for each answer option to make it easier for children to answer.

For the present study, the following question of this questionnaire was used to assess the geographical environment: Participants were asked: What area of Madrid do you live in? Response options were: 1 . City center, 2. Outskirts of the city, 3. Bedroom town, 4. Village. These options were categorized as: City/Urban (1. City center, 2. Outskirts of the city), Residential area/Outside city (3. Bedroom town), and Rural/Village (4. Village).

\subsubsection{Modes of Commuting to School}

The validated EYHS questionnaire [21] was used, following the same procedure described in the previous section. For the present study, the following question of this questionnaire was used to assess the modes of transport to school. Participants were asked: How do you usually go to school? Response options were: 1 . Car or motorcycle, 2. Bus or train, 3. Bicycle, 4. Walking. These options were categorized as active commuting (3. Bicycle, 4 . Walking) and passive commuting/motor vehicle (1. Car or motorcycle, 2. Bus or train).

\subsection{Data Analysis}

Normality tests, symmetry studies, and kurtosis of all variables were verified, verifying that they did not deviate significantly from the normal distribution. Descriptive quantitative statistics, frequency analyses, and contingency tables were also carried out in the variables of physical activity, gender, geographical environment, and type of commuting to school. Student's t-test for independent samples was used to examine gender differences in the physical activity variables, while the analysis of the variance (ANOVA) was used to examine differences in physical activity levels by the type of commuting to school. Pearson correlation was used to analyze the correlations between the variables of daily physical activity and physical activity during commuting to school. The chi-square test was used to study the differences in the distribution of the sample by gender, geographical environment, and type of commuting to school. Data analyses were carried out using SPSS 23.0, and the level of significance was set at $p<0.05$. There were no missing values in the accelerometry data $(n=455)$ but EYHS questionnaire was completed by only 387 of the 455 participants $(15 \%$ of missing values in the questionnaire) because the other 68 children did not attend the questionnaire evaluation session.

\section{Results}

Only $34.7 \%$ of participants fulfilled the international recommendations of healthy physical activity, while the other $65.3 \%$ did not do enough physical activity according to the international recommendations. In Table 1, we can see the average daily minutes dedicated to each intensity of activity, counts/minutes, and the steps taken by the children of the study during the school days. There were significant differences $(p \leq 0.001)$ in all the variables analyzed, with higher average values in boys, except for the sedentary time that was higher in girls (1170.37 \pm 114.30 versus $1129.38 \pm 113.71)$. Regarding the physical activity levels measured during commuting to school in the school days, there were significant differences between both genders in sedentary time (higher in girls, $p=0.024$ ) and in counts/minute (higher in boys, $p=0.001$ ). 
Table 1. Physical activity in school days by gender.

\begin{tabular}{lcccc}
\hline \multicolumn{1}{c}{ Daily } & Girls $(\boldsymbol{n}=\mathbf{2 4 7})$ & Boys $(\boldsymbol{n}=\mathbf{2 0 8})$ & $\boldsymbol{t}$ & $\boldsymbol{p}$ \\
\hline Sedentary time (min/day) & $1170.37 \pm 114.30$ & $1129.38 \pm 113.71$ & 3.820 & $\leq \mathbf{0 . 0 0 1}$ \\
VPA (min/day) & $16.48 \pm 12.53$ & $23.49 \pm 17.00$ & -4.929 & $\leq \mathbf{0 . 0 0 1}$ \\
MVPA (min/day) & $62.28 \pm 28.13$ & $85.81 \pm 33.61$ & -8.009 & $\leq \mathbf{0 . 0 0 1}$ \\
Intensity (counts/min) & $535.05 \pm 146.08$ & $645.71 \pm 162.50$ & -7.646 & $\leq \mathbf{0 . 0 0 1}$ \\
Steps (number) & $10562.27 \pm 2770.19$ & $12831.75 \pm 3200.58$ & -8.107 & $\leq \mathbf{0 . 0 0 1}$ \\
During commuting to school & Girls $(\boldsymbol{n}=\mathbf{2 4 7})$ & Boys $(\boldsymbol{n}=\mathbf{2 0 8})$ & $\boldsymbol{t}$ & $\boldsymbol{p}$ \\
Sedentary time (min/day) & $45.29 \pm 9.35$ & $43.16 \pm 10.61$ & 2.270 & $\mathbf{0 . 0 2 4}$ \\
VPA (min/day) & $0.79 \pm 1.30$ & $0.95 \pm 2.17$ & -0.977 & 0.329 \\
MVPA (min/day) & $3.10 \pm 3.20$ & $3.56 \pm 4.09$ & -1.356 & 0.176 \\
Intensity (counts/min) & $518.95 \pm 298.73$ & $623.33 \pm 360.10$ & -3.354 & $\mathbf{0 . 0 0 1}$ \\
Steps (number) & $619.06 \pm 459.05$ & $702.26 \pm 518.58$ & -1.815 & 0.070 \\
\hline
\end{tabular}

Values expressed in mean \pm SD. VPA: vigorous physical activity, MVPA: moderate to vigorous physical activity. $p<0.05$ in bold.

In Table 2, we can see the correlations between daily physical activity and physical activity during commuting to school on school days. There was a significant positive correlation between the daily MVPA and the MVPA during commuting to school $(r=0.324, p \leq 0.001)$, and also between the daily MVPA and the steps during commuting to school $(r=0.245, p \leq 0.001)$. Moreover, daily MVPA was significantly and negatively correlated with sedentary time during commuting to school $(r=-0.124$, $p=0.008$ ). Therefore, those who were more active in the whole day were also more active and less sedentary during commuting to the school.

Table 2. Correlations between daily physical activity and physical activity during commuting to school on school days $(\mathrm{N}=455)$.

\begin{tabular}{lccc}
\hline & $\begin{array}{c}\text { School Sedentary Time } \\
\text { (min/day) }\end{array}$ & $\begin{array}{c}\text { School MVPA } \\
\text { (min/day) }\end{array}$ & $\begin{array}{c}\text { School Steps } \\
\text { (number) }\end{array}$ \\
\hline Daily Sedentary Time (min/day) & $0.736(\mathbf{\leq 0 . 0 0 1 )}$ & $-0.026(0.578)$ & $0.004(0.927)$ \\
Daily MVPA (min/day) & $-0.124(\mathbf{0 . 0 0 8})$ & $0.324(\leq \mathbf{0 . 0 0 1 )}$ & $0.245(\leq \mathbf{0 . 0 0 1 )}$ \\
Daily Steps (number) & $-0.133(\mathbf{0 . 0 0 5})$ & $0.266(\leq \mathbf{0 . 0 0 1})$ & $0.287(\leq \mathbf{0 . 0 0 1 )}$ \\
\hline
\end{tabular}

Values expressed in Pearson's $r(p)$. MVPA: moderate to vigorous physical activity. $p<0.05$ in bold.

The sample size in Tables 3 and 4 was 387 instead of 455 because 68 participants did not answer these questions. In Table 3, the school days' physical activity during commuting to school was analyzed according to the type of commuting. There were significant differences between those who used a motor vehicle with respect to those who walked to school. Children who walked to school accumulated significantly more MVPA and a higher number of steps than those who used a motor vehicle to commute to school $(p \leq 0.001)$.

In Table 4, the distribution of the sample was analyzed. Regarding the distribution of geographical environment by sex, there were no significant differences. The most frequent geographical environment among the participants was city/urban $(n=168)$, while the least frequent was residential area/outside city $(n=67)$. With regard to the distribution of commuting to school by sex, it was noteworthy that no subject used the bicycle to go to school, as all the participants used a motor vehicle $(55.6 \%)$ or walked $(44.4 \%)$. Although passive commuting was the most frequent mode, there were no significant differences between sexes $\left(\chi^{2}=0.352, p>0.05\right)$. Regarding the distribution of the sample by type of commuting to school and geographical environment, it was noteworthy that active commuting to school was significantly $(p \leq 0.001)$ less frequent in those children who lived in a rural environment $(22.4 \%)$ than in those who lived in the city $(57.1 \%)$ or in a residential area $(62.7 \%)$. 
Table 3. School days' physical activity during commuting to school, by the type of commuting.

\begin{tabular}{lccccc}
\hline & Commuting & $\boldsymbol{N}$ & Mean & $\boldsymbol{F}$ & $\boldsymbol{p}$ \\
\hline Sedentary & Motor vehicle & 215 & $44.85 \pm 9.91$ & & \\
time (min/day) & Walking & 172 & $43.21 \pm 9.76$ & 2.637 & 0.105 \\
& $N$ & 387 & $44.12 \pm 9.86$ & & \\
MVPA & Motor vehicle & 215 & $2.71 \pm 2.94$ & & \\
(min/day) & Walking & 172 & $4.03 \pm 4.04$ & 13.924 & $\leq \mathbf{0 . 0 0 1}$ \\
& $N$ & 387 & $3.29 \pm 3.53$ & & \\
Intensity & Motor vehicle & 215 & $494.93 \pm 257.88$ & & \\
(counts/min) & Walking & 172 & $642.81 \pm 367.68$ & 21.198 & $\leq \mathbf{0 . 0 0 1}$ \\
& $N$ & 387 & $560.91 \pm 319.83$ & & \\
Steps & Motor vehicle & 215 & $551.59 \pm 374.41$ & & \\
(number) & Walking & 172 & $766.74 \pm 539.68$ & 21.338 & $\leq \mathbf{0 . 0 0 1}$ \\
& $N$ & 387 & $647.21 \pm 467.13$ & & \\
\hline
\end{tabular}

Values expressed in Mean \pm SD. MVPA: moderate to vigorous physical activity. F= Fisher-Snedecor variance estimator; $p<0.05$ in bold.

Table 4. Distribution of the sample by gender, geographical environment, and type of commuting to school.

\begin{tabular}{|c|c|c|c|c|c|c|c|}
\hline & & & \multicolumn{2}{|c|}{ Gender } & \multirow{2}{*}{$N$} & \multicolumn{2}{|c|}{$x^{2}$} \\
\hline & & & Girls & Boys & & Value & $p$ \\
\hline \multirow{6}{*}{$\begin{array}{l}\text { Geographical } \\
\text { environment }\end{array}$} & \multirow{4}{*}{\multicolumn{2}{|c|}{$\begin{array}{c}\text { City/urban } \\
\text { Residential area/outside city } \\
\text { Rural/village } \\
N\end{array}$}} & $96(45.9)$ & $72(40.4)$ & 168 & & \\
\hline & & & $35(16.8)$ & $32(18.0)$ & 67 & 1.193 & 0.551 \\
\hline & & & $78(37.3)$ & $74(41.6)$ & 152 & & \\
\hline & & & $209(100)$ & $178(100)$ & 387 & & \\
\hline & & & \multicolumn{2}{|c|}{ Gender } & \multirow{2}{*}{$N$} & \multicolumn{2}{|c|}{$x^{2}$} \\
\hline & & & Girls & Boys & & Value & $p$ \\
\hline \multirow{5}{*}{ Commuting to } & oschool & Motor vehicle & $119(56.9)$ & $96(53.9)$ & 215 & 0352 & 0608 \\
\hline & & Walking & $90(43.1)$ & $82(46.1)$ & 172 & 0.352 & 0.608 \\
\hline & $N$ & & $209(100)$ & $178(100)$ & 387 & & \\
\hline & & \multicolumn{3}{|c|}{ Geographical environment } & $N$ & \multicolumn{2}{|c|}{$x^{2}$} \\
\hline & & City/Urban & $\begin{array}{l}\text { Residential } \\
\text { area/Outside } \\
\quad \text { city }\end{array}$ & Rural/Village & & Value & $p$ \\
\hline \multirow{3}{*}{$\begin{array}{l}\text { Commuting } \\
\text { to school }\end{array}$} & Motor vehicle & $72(42.9)$ & $25(37.3)$ & $118(77.6)$ & 215 & \multirow{3}{*}{50.003} & \multirow{3}{*}{$\leq 0.001$} \\
\hline & Walking & $96(57.1)$ & $42(62.7)$ & $34(22.4)$ & 172 & & \\
\hline & $N$ & $168(100)$ & $67(100)$ & $152(100)$ & 387 & & \\
\hline
\end{tabular}

Values expressed in mean \pm SD. MVPA: moderate to vigorous physical activity. $\mathrm{F}=$ Fisher-Snedecor variance estimator, $p<0.05$ in bold. Values expressed in frequencies (\%). $\chi^{2}=$ Chi-squared. $p<0.05$ in bold.

\section{Discussion}

Regarding compliance with the international recommendations of healthy physical activity, only $34.7 \%$ of the children fulfilled said recommendations, and of those who did so were more boys than girls, which confirms the data obtained in other studies [22-28]. Although the average physical activity of both sexes makes us see how the recommended values are exceeded, we must bear in mind that a large sector of the analyzed population does not comply with them.

Regarding the levels of MVPA during commuting to school, they were very low (girls: $3.10 \pm 3.20 \mathrm{~min}$, boys: $3.56 \pm 4.09 \mathrm{~min}$ ), as was the case of the number of steps taken at that time (girls: $619 \pm 459.05$, boys: $702.26 \pm 518.58$ ). These low values are similar to those found by Merom et al [16], who indicated that walking/cycling only and in combination with bus/car were of short duration (median 7 or $4 \mathrm{~min}$, respectively). One possible explanation for these low values is that the time for 
commuting to school is lower than one hour. However, this low time dedicated to MVPA at the time of commuting to school is an excellent opportunity to increase the weekly time of physical activity of schoolchildren, as we found in our results with the significant positive correlations between the daily MVPA and the MVPA during commuting to school $(r=0.324, p \leq 0.001)$, and also between the daily MVPA and the steps during commuting to school $(r=0.245, p \leq 0.001)$. This time dedicated to active commuting can be, if small changes are made in the intensity of the commuting, a great contribution in the overall MVPA of the children, as many children only have the opportunity to be active during a trip to school, a school recess and a Physical Education session $[25,29]$. This would mean a change in the urban and rural structures, in the educational policies and in the organization of the educational centers in order to promote active commuting.

It should also be noted that, according to WHO [5], if children are currently doing no physical activity, doing amounts below the recommended levels will bring more benefits than doing none at all, and it should also be noted that amounts of physical activity greater than $60 \mathrm{~min}$ provide additional health benefits. Therefore, doing more physical activity during commuting to school will be beneficial for the children, even if this physical activity is not very high, because every minute of physical activity has a positive value for health.

In the present study, only $44.4 \%$ walked to school, while $55.6 \%$ used a car. To better understand these results, it is important to put them in context, comparing them with previous studies carried out in several countries. When comparing our results with the results of the Spanish study ALADINO [30], we can observe a decrease in active commuting, because in the study ALADINO [30] the most frequent mean of commuting to school was walking ( $62.8 \%$ go to school walking and $65.7 \%$ return walking), followed by car (33.1\% go to school in car and $30.1 \%$ return in car). These results are similar to the data obtained by D'Haese et al. [31], as they stated that approximately $60 \%$ of children in Belgium use active commuting to attend school. Nevertheless, Merom et al. [16] found that only $22 \%$ of children used active commuting in Australia. In addition, Sirard and Slater [10] carried out a global review about the use of active commuting to school and indicated that active commuting had dropped from $40.7 \%$ to $12.9 \%$, while passive commuting has gone from $17.1 \%$ to $55.0 \%$ between 1969 and 2001 . The research of Pizarro et al. [32] in Portugal also shows a descending line, since active commuting and specifically walking to school fell from $27 \%$ in 1991 to $19 \%$ in 2001, while passive commuting increased from $23 \%$ to $49 \%$.

There are several studies that affirm that this decrease in the use of active commuting is the result of a social change, a population increase, environmental and personal factors, as well as increased traffic in cities and bad management of infrastructure for bicycle users [33-35]. However, it seems that some countries, such as Denmark and the Netherlands, have not noticed this decrease due to the strong tradition among the population [33]. In fact, Andersen et al. [36], in a study with adolescents conducted in 18 schools in Denmark, showed that there was a high percentage of active commuting use (around $64 \%$ of the population). Considering these differences between countries, future studies should design and apply programs of promotion of active commuting following the example of the countries where active commuting is more frequent.

In our study, we have been able to confirm that the participants from rural areas used less active commuting than those living in urban areas. This seems to be a paradox, since apparently rural areas have better conditions for active commuting [1,35]. However, maybe urban areas nowadays are more walkable than rural areas due to better connectivity, and maybe rural areas do not offer better conditions for active commuters to go to school, where the distance could be also an important factor. As some authors $[37,38]$ showed, when the distance to school is higher, the active commuting is lower, indicating that distances between $1.5-2 \mathrm{~km}$ are the best to favor the increase of active commuting. These authors also pointed out that when the distance is higher than $6 \mathrm{~km}$, passive commuting is very frequent.

Regarding the limitations of the study, distance to school and parent commuting habits were not considered in this study. Hence, it is recommended that these aspects are considered in future studies 
in order to increase the knowledge of the children's socio-environmental influences on commuting to school. The main strength of this study was the use of reliable and valid instruments to analyze physical activity, commuting to school, and geographical environment in Spanish nine-year-old children. The main practical implication of the results of this study is that active commuting to school means increasing levels of physical activity in both sexes. Moreover, rural environments despite having less traffic density, presented lower rates of children's active commuting to school. Therefore, active commuting to school should be encouraged, particularly in rural areas, applying strategies for this purpose. For instance, the organization of big sporting events [39] and the involvement of the community through volunteers who accompany the children to schools from meeting points, in order to increase physical activity as part of a group [40,41].

\section{Conclusions}

This study shows that active commuting to school increases the levels of physical activity, with a positive correlation between these two factors. The geographical environment influences the way in which children commute to school, being active commuting to school significantly less frequent in those children who live in a rural environment. Therefore, the traditional use of active commuting in rural environments seems to have decreased in comparison to urban environments, which seems to evidence a social change regarding the use of active commuting. As active commuting to school means increasing levels of physical activity in both sexes, strategies should be implemented in order to encourage active commuting to schools, contributing at the same time to greater mobility and sustainability of future generations, and generating a positive impact on public and environmental health. Nonetheless, further research is required to assess the effects of external factors on the relationships among distance, active commuting probability, and physical activity.

Author Contributions: Writing—original draft preparation, J.M.-M., S.A., S.G.-V., and G.F.L.-S.; Writing一review and editing, J.M.-M., S.A., S.G.-V., and G.F.L.-S.

Funding: This research received no external funding.

Acknowledgments: We would like to acknowledge all EYHS group leaders who assisted us in implementing the study. Finally, to all participating schools, which made this study possible.

Conflicts of Interest: The authors declare no conflict of interest.

\section{References}

1. Mota, J.; Gomes, H.; Almeida, M.; Ribeiro, J.C.; Santos, P. Leisure time physical activity, screen time, social background and environmental variables in adolescents. Pediatr. Exerc. Sci. 2007, 19, 279-290. [CrossRef] [PubMed]

2. Heath, G.W.; Parra, D.C.; Sarmiento, O.L.; Andersen, L.B.; Owen, N.; Goenka, S.; Montes, F.; Brownson, R.C. Evidence-based intervention in physical activity: Lessons from around the world. Lancet 2012, 380, $272-281$. [CrossRef]

3. Reynolds, R.; McKenzie, S.; Allender, S.; Brown, K.; Foulkes, C. Systematic review of incidental physical activity community interventions. Prev. Med. 2014, 67, 46-64. [CrossRef] [PubMed]

4. Stanley, R.; Maher, C.; Dollman, J. Modelling the contribution of walking between home and school to daily physical activity in primary age children. BMC Public Health 2015, 15, 445. [CrossRef]

5. WHO. Global Recommendations on Physical Activity for Health; WHO Press: Geneva, Switzerland, 2010.

6. Faulkner, G.E.; Buliung, R.N.; Flora, P.K.; Fusco, C. Active school transport, physical activity levels and body weight of children and youth: A systematic review. Prev. Med. 2009, 48, 3-8. [CrossRef]

7. Larouche, R.; Saunders, T.J.; Faulkner, G.E.J.; Colley, R.; Tremblay, M. Associations between active school transport and physical activity, body composition, and cardiovascular fitness: A systematic review of 68 studies. J. Phys. Act. Health 2014, 11, 206-227. [CrossRef]

8. Villa-González, E.; Barranco-Ruiz, Y.; Evenson, K.R.; Chillón, P. Systematic review of interventions for promoting active school transport. Prev. Med. 2018, 111, 115-134. [CrossRef] 
9. Chillon, P.; Evenson, K.R.; Vaughn, A.; Ward, D.S. A systematic review of interventions for promoting active transport to school. Int. J. Behav. Nutr. Phys. Act. 2011, 8, 1-17. [CrossRef]

10. Sirard, J.; Slater, M. Walking and bicycling to school: A review. Am. J. Lifestyle Med. 2008, 2, 372-396. [CrossRef]

11. Ikeda, E.; Hinckson, E.; Witten, K.; Smith, M. Associations of children's active school travel with perceptions of the physical environment and characteristics of the social environment: A systematic review. Health Place 2018, 54, 118-131. [CrossRef]

12. Rodríguez-López, C.; Salas-Fariña, Z.M.; Villa-González, E.; Borges-Cosic, M.; Herrador-Colmenero, M.; Medina-Casaubón, J.; Ortega, F.B.; Chillón, P. The threshold distance associated with walking from home to school. Health Educ. Behav. 2017, 44, 857-866. [CrossRef] [PubMed]

13. Hinckson, E.A.; McGrath, L.; Hopkins, W.; Oliver, M.; Badland, H.; Mavoa, S.; Witten, K.; Kearns, R.A. Distance to school is associated with sedentary time in children: Findings from the URBAN study. Front. Public Health 2014, 2, 151. [CrossRef] [PubMed]

14. European Environment Agency. Air Quality in Europe-2017 Report; European Environment Agency: Copenhagen, Denmark, 2017.

15. McMillan, T. The relative influence or urban form on a child's travel mode to school. Transp Res. Part. A Policy Pract. 2007, 41, 69-79. [CrossRef]

16. Merom, D.; Tudor-Locke, C.; Bauman, A.; Rissel, C. Active commuting to school among NSW primary school children. Implications for public health. Health Place 2006, 12, 678-687. [CrossRef] [PubMed]

17. Bringolf-Isler, B.; Grize, L.; Mäder, U.; Ruch, N.; Sennhauser, F.H.; Braun-Fahrländer, C. Personal and environmental factors associated with active commuting to school in Switzerland. Prev. Med. 2008, 46, 67-73. [CrossRef]

18. Ikeda, E.; Hinckson, E.; Witten, K.; Smith, M. Assessment of direct and indirect associations between children active school travel and environmental, household and child factors using structural equation modelling. Int. J. Behav. Nutr. Phys. Act. 2019, 16, 32. [CrossRef]

19. Ekelund, U.; Sardinha, L.; Anderssen, S.; Harro, M.; Franks, P.W.; Brage, S.; Cooper, A.R.; Andersen, L.B.; Riddoch, C.; Froberg, K. Associations between objectively assessed physical activity and indicators of body fatness in 9- to 10-y-old European children: A population-based study from 4 distinct regions in Europe (the European Youth Heart Study). Am. J. Clin. Nutr. 2004, 80, 584-590. [CrossRef]

20. Andersen, L.B.; Harro, M.; Sardinha, L.B.; Froberg, K.; Ekelund, U.; Brage, S.; Anderssen, S.A. Physical activity and clustered cardiovascular risk in children: A cross-sectional study (The European Youth Heart Study). Lancet 2006, 368, 299-304. [CrossRef]

21. Ommundsen, Y.; Page, A.; Ku, P.W.; Cooper, A.R. Cross-cultural, age and gender validation of a computerised questionnaire measuring personal, social and environmental associations with children's physical activity: The European Youth Heart Study. Int. J. Behav. Nutr. Phys. Act. 2008, 5, 1-14. [CrossRef]

22. Riddoch, C.; Mattocks, C.; Deere, K.; Saunders, J.; Kirkby, J.; Tilling, K.; Leary, S.; Blair, S.; Ness, A. Objective measurement of levels and patterns of physical activity. Arch. Dis. Child. 2007, 92, 963-969. [CrossRef]

23. Troiano, R.P.; Berrigan, D.; Dodd, K.W.; Masse, L.C.; Tilert, T.; McDowell, M. Physical activity in the United States measured by accelerometer. Med. Sci. Sports Exerc. 2008, 40, 181-188. [CrossRef] [PubMed]

24. Martínez-Gómez, D.; Ruiz, J.R.; Gómez-Martinez, S.; Chillon, P.; Rey-López, J.P.; Díaz, L.E.; Castillo, R.; Veiga, O.L.; Marcos, A.; AVENA Study Group. Active commuting to school and cognitive perfomance in adolescent the AVENA study. Arch. Pediatr. Adolesc. Med. 2011, 165, 300-305. [CrossRef] [PubMed]

25. Ridgers, N.; Saint-Maurice, P.; Welk, G.; Siahpush, M.; Huberty, J. Differences in physical activity during school recess. J. Sch. Health 2011, 81, 545-551. [CrossRef] [PubMed]

26. Aznar, S.; Naylor, P.; Silva, P.; Pérez, M.; Angulo, T.; Laguna, M.; Lara, M.T.; López-Chicharro, J. Patterns of physical activity in Spanish children: A descriptive pilot study. Child. Care Health Dev. 2011, 37, 322-328. [CrossRef] [PubMed]

27. López Sánchez, G.F.; González Víllora, S.; Díaz Suárez, A. Level of habitual physical activity in children and adolescents from the Region of Murcia (Spain). SpringerPlus 2016, 5, 1-6. [CrossRef] [PubMed]

28. López-Sánchez, G.F.; Emeljanovas, A.; Miežiene, B.; Díaz-Suárez, A.; Sánchez-Castillo, S.; Yang, L.; Roberts, J.; Smith, L. Levels of physical activity in Lithuanian adolescents. Medicina 2018, 54, 84. [CrossRef] [PubMed] 
29. Mota, J.; Silva, P.; Santos, M.P.; Ribeiro, J.C.; Oliveira, J.; Duarte, J.A. Physical activity and school recess time: Differences between the sexes and the relationship between children's playground physical activity and habitual physical activity. J. Sports Sci. 2005, 23, 269-275. [CrossRef]

30. ALADINO. Estudio de Vigilancia del Crecimiento, Alimentación, Actividad Física, Desarrollo Infantil y Obesidad en España 2013; Agencia Española de Consumo, Seguridad Alimentaria y Nutrición-Ministerio de Sanidad, Servicios Sociales e Igualdad: Madrid, Spain, 2014.

31. D’Haese, S.; De Meester, F.; De Bourdeaudhuij, I.; Deforche, B.; Cardon, G. Criterion distances and environmental correlates of active commuting to school in children. Int. J. Behav. Nutr. Phys. Act. 2011, 8, 1-10. [CrossRef]

32. Pizarro, A.; Ribeiro, J.; Marques, E.; Mota, J.; Santos, P. Is walking to school associated with improved metabolic health? Int. J. Behav. Nutr. Phys. Act. 2013, 10, 1-7. [CrossRef]

33. Delinger, A.; Stanton, C. Barriers to children walking and biking to school. Morb. Mortal Wkly. Rep. 2002, 51, 701-704.

34. Lawlor, D.; Ness, A.; Cope, A.; Davis, A.; Insall, P.; Riddoch, C. The challenges of evaluating environmental interventions to increase population level os physical activity: The case of the UK National cycle network. J. Epidemiol. Community Health 2003, 57, 96-101. [CrossRef] [PubMed]

35. Timperio, A.; Crawford, D.; Telford, A.; Salmon, J. Perceptions about the local neighbourhood and walking and cycling among children. Prev. Med. 2004, 38, 39-47. [CrossRef] [PubMed]

36. Andersen, L.B.; Lawlor, D.A.; Cooper, A.R.; Froberg, K.; Anderssen, S.A. Physical fitness in relation to transport to school in adolescents: The Danish youth and sports study. Scand. J. Med. Sci. Sports 2009, 19, 406-411. [CrossRef] [PubMed]

37. Timperio, A.; Ball, K.; Salmon, J.; Roberts, R.; Giles-Corti, B.; Simmons, D.; Baur, L.A.; Crawford, D. Personal, family, social, and environmental correlates of active commuting to school. Am. J. Prev. Med. 2006, 30, 45-51. [CrossRef] [PubMed]

38. Panter, J.; Jones, A.; Van Sluijs, E.; Griffin, S. The influence of distance to school on the associations between active commuting and physical activity. Pediatr. Exerc. Sci. 2011, 23, 72-86. [CrossRef]

39. López-Sánchez, G.F.; Gordon, D.; Hodgson, L.; Stubbs, B.; Gardner, B.; Smith, L. The effect of the 2016 Rio de Janeiro Olympics on spectators' physical activity. Atena J. Sports Sci. 2019, 1, 1-8.

40. Davison, K.; Lawson, C. Do attributes in the physical environment influence children's physical activity? A review of the literature. Int. J. Behav. Nutr. Phys. Act. 2006, 3, 1-17. [CrossRef]

41. Trott, M.; Smith, L. What are the associations between extroversion, enjoyment, and wellness in group vs non-group physical activity? A pilot study. Atena J. Sports Sci. 2019, 1, 1-11. 